\title{
Modeling the transfer of potassium monophosphate with irrigation water in drip irrigation and sprinkling
}

\author{
Victor Alekseev ${ }^{1,}{ }^{*}$, Rustam Aleksandrov ${ }^{1}$, Sergey Vasiliev $^{1}$, Olga Kharitonova $^{1}$, Vladimir \\ Philippov $^{2}$, and $V . V$. Alekseev ${ }^{3}$ \\ ${ }^{1}$ Chuvash State University named after I N Ulyanov, 15, Moskovskij Ave., Cheboksary, 428015, \\ Russia \\ ${ }^{2}$ Cheboksary Cooperative Institute (branch) of Russian University of Cooperation, 24, M. Gorkogo \\ Ave., Cheboksary, 428025, Russia \\ ${ }^{3}$ Chuvash State Pedagogical University named after I Ya Yakovlev, 38, Karla Marksa st., \\ Cheboksary, 428000, Russia
}

\begin{abstract}
Fertigation practically always allows us to simultaneously solve a wide range of problems of supplying plants with mineral substances. It is due to the possibility to localize the application area in accordance with the structural features of the root system of the plant. A review of the studies on modeling and calculating the transfer of nutrients shows that spatial inhomogeneity of nutrients distribution may lead to their excess in wrong soil areas. Time intervals and volumes of applying dissolved fertilizers determine the not yet completely studied dynamics of concentration of the nutrition elements in the root area. Formation of the root system is under a strong influence of the boundaries of the wetting contour, since after the irrigation and soil drying nutrients tend to concentrate in this particular area. The results of transfer modeling showed significant differences in the final distribution of potassium monophosphate in soil depending on the initial distribution of moisture there. This can be pre-estimated and calculated. The designed software programme for modeling nutrients transfer with irrigation water allows the user to set various initial wetting gradients depending on the depth, the intervals between the drippers, the intensity and duration of watering. The calculations are made considering the basic hydrophysical soil characteristic and hydraulic conductivity function. The software is equipped with an interactive graphic interface for primary data processing, soil profile discretization and graphic representation of the results.
\end{abstract}

\section{Introduction}

Fertigation as a method of applying fertilizers with irrigation water is widely spread in both Russian and foreign agriculture. Fertigation is of particular interest in connection with drip irrigation. A growing demand for this method of applying dissolved nutrients with irrigation

\footnotetext{
*Corresponding author: av77@list.ru
} 
water almost always enables us to simultaneously solve a wide range of problems related to supplying plants with minerals. At present a sufficient number of appliances (pumps, injectors and similar) exist enabling plants irrigation and nutrition without a so called "stress" [1]. To the main listed advantages of using such appliances we can refer ecological compatibility and fertilizing cost minimization due to the possibility to localize the fertilizer application area in accordance with the root system peculiarities; high control precision of the applied fertilizer concentration and of the time of the application which is done in a timely manner and according to the growth phases.

Along with the frequent practical application of fertigation in agriculture quite a number of problems still require a solution. Spatial inhomogeneity in the nutrients distribution may lead to their excess in wrong areas or, vice verse, their insufficient concentration in necessary ones; volume and intervals of applying dissolved fertilizers determine the not yet completely studied dynamics of concentration of the plant food compounds in the rooting zone. Final distribution of the applied nutrients is under a strong influence of the initial soil water content in connection with the depth and the current salt distribution. In spite of their significance the aspects named have not been properly researched and have no analytical solution. In reference to the above said mass and salt transfer modeling and application of numerical methods are quite topical. Solving these problems allows us to make the irrigation process more economical, highly automated and to create favorable conditions for plant growth and development. Theoretical and applied questions of drip irrigation are widely covered in scientific research. These include selection of irrigation standards, various planting types with a change to the irrigation standards, modeling geometrical parameters of the wetting contour and of the efficient ameliorants application [2-5]. Basing on the laws of physics and mathematical statistics different types of models have been obtained to determine the geometrical characteristics of the contours [6]. The work [7] dwells upon the influence of certain soil and water properties on the wetting contours shaping. The study [8] determines the moisture values at which cracks in soil remain partially open even when the water saturation of soil is relatively high. Soil characteristics to be taken into account while researching and estimating the wetting contour formation have also been determined [9]. These include such widely known factors as minimal moisture rate and mechanical soil composition.

Summarizing the brief survey of the relevant studies we can state that at the present stage in research they already contain a well-formed mathematical apparatus enabling us to decide upon the wetting contours, but not the mass and salt transfer for drip irrigation. The analysis also showed that in order to increase the efficiency of fertigation modeling in drip irrigation the influence of the initial conditions upon the final nutrient distribution is of great importance. Thus, the aim of the present work is to study the peculiarities of nutrient distribution in the soil profile depending on the initial soil water level at varying depth.

\section{Materials and methods}

To study the mass transfer in drip irrigation potassium monophosphate has been used as a nutritive substance. This fertilizer is wide-spread and known to many agriculturalists. It is frequently used to feed plants since it allows changing soil quality in a short period of time. The main components of it are phosphorus and potassium. These elements have low mobility in soil, so it is effective to apply them with irrigation water. Potassium monophosphate can dissolve well in water. The dosage varies for different crops but the average one is 5-30 g per 101 of water. Adding potassium monophosphate to irrigation water changes some water properties important for modeling. Water density rises insignificantly - only by fractions of percent - which can be neglected. Water viscosity and the contact angle of wetting change by $1-2 \%$. Osmotic pressure rises by $3-7 \%$. The surface 
tension coefficient decreases by tens of percent. The majority of the parameters mentioned can be quickly and easily measured by classical physical methods $[10,11]$.

Hydraulic conductivity function shows how water with dissolved in it nutrients will migrate in the soil under the pressure gradient. It is natural that with a change in this function volumes of water moving from one point in space to another also change. While considering energy of soil water [12] we only take into account $\psi^{\prime}-$ a potential conditioned by the interaction of soil water and the solid phase of soil, $\psi^{\prime \prime}-$ a potential conditioned by the interaction of soil water with soil air and $\psi^{\prime \prime \prime}-$ a potential due to osmotic pressure. Then the relation of the soil water potential $\psi$ and soil moisture volume $w$ (Soil Water Retention Curve - SWRC) can be presented as:

$$
\psi=\psi^{\prime}+\psi^{\prime \prime}+\psi^{\prime \prime \prime}=\frac{A \Omega_{0}^{3}}{\rho w^{3}}+\frac{\Omega_{0} \sigma_{l g}}{\rho} \cdot D\left(w, \Pi_{0}\right)+\frac{R T}{\rho}\left(\frac{C}{M^{*}}+\frac{C^{2} \rho}{M\left(\rho^{*}\right)^{2}}\left(\frac{1}{2}-\mu\right)\right),
$$

where $\Omega_{0}$ is volume specific surface area, $w-$ moisture volume, $\sigma_{l g}-$ surface tension coefficient (water - air), $\rho$ - water density, $M$ - molar mass of water, $\rho^{*}-$ potassium monophosphate density, $M^{*}$ - molar mass of potassium monophosphate, $C$ - potassium monophosphate concentration, $R$ - universal gas constant, $T$ - temperature, $\mu$ and $A-$ constant values, $D\left(w, \Pi_{0}\right)$ - a function basing on the granulometric composition.

As a result of adding potassium monophosphate to the irrigation water we can observe a change in the hydraulic conductivity function which is the relation between the hydraulic conductivity coefficient and the soil water retention. Figure 1 illustrates the change in the hydraulic conductivity function of light-grey forest soil when added $1 \mathrm{~g}$ of potassium monophosphate per 11 water.

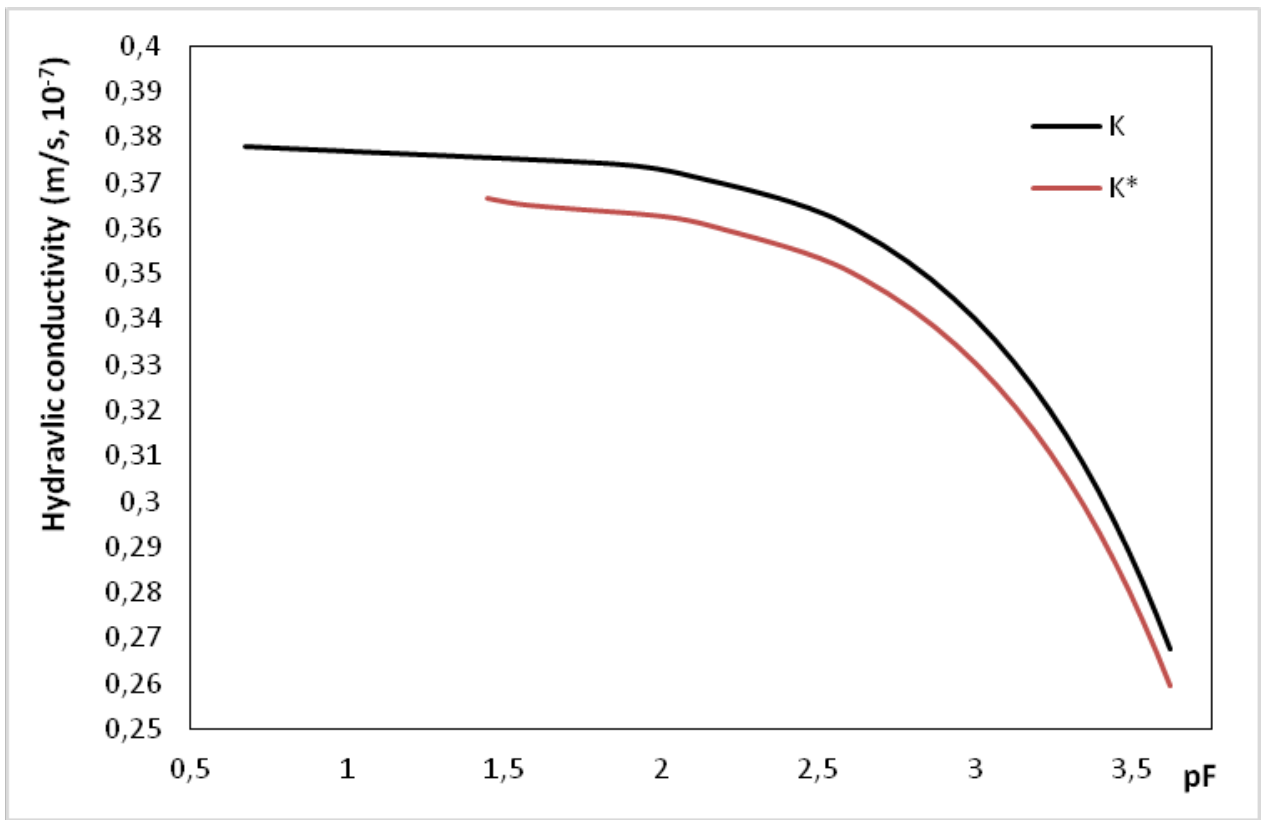

Fig. 1. Hydraulic conductivity changing under the influence of potassium monophosphate ( $K$ refers to pure water, $K^{*}$ refers to water with potassium monophosphate)

The calculations show that with a change in moisture volume $w$ from 0.3 to 0.5 the average change of the hydraulic conductivity coefficient has made up 3-8\% and of the soil water retention - between 2 and $116 \%$ [13]. In order to achieve the study aim a software 
programme has been designed by the authors which allows modeling soil water dynamics together with figuring the wetting contours and nutrients concentration enclosure lines. This programme uses Darcy formula where pressure difference of soil water in adjusting soil patches is calculated by the formula (1), thus, taking into account the soil type, its porosity and granulometric composition. These parameters as well as soil water value according to the depth are given as initial conditions.

The uniform grid function used in the algorythm to enter all the three coordinates has $\mathrm{n}^{3}$ nodes taken into consideration while calculating at each iteration (n equals the number of points on each coordinate). Despite the high operating speed of modern computers with such an amount of grid nodes numerical computatons still take up a considerable time. The dynamics of water distribution in soil in drip irrigation has been calculated following the given algorythm: a certain amount of water was supplied with the assigned speed and interval onto the preliminary defined surface grid nodes (a cube with $\Delta \mathrm{h}=1 \mathrm{~mm}$ edges). To calculate the amount of fluid flowing from a node/ layer to an adjusting one Darcy equation has been used. To calculate the transfer between vertically adjusting layers a gravity potential $\mathrm{g} \Delta \mathrm{h}$ has been added.

Soil moisture volume $(w)$ refers to the volume of water in a volume unit of soil space. This value changes with every new calculation cycle. At the first approximation we will consider it as a total of moisture volume already existing in the soil $w_{0}$ with the potassium monophosphate concentration $C_{0}$ and the external water $w^{*}$ with the potassium monophosphate concentration $C^{*}$ according to the Darcy law. Then it can be put as:

$$
w=w_{0}+w^{*}
$$

On account of the fact that a drip irrigation process may proceed rather slowly (in our case it takes about 24 hours) we will approximately consider the fluids to be able to mix up. So, the obtained potassium monophosphate concentration in a single calculated volume can be presented as:

$$
C=\frac{C_{0} w_{0}+C^{*} w^{*}}{w_{0}+w^{*}}
$$

\section{Results and Discussions}

In order to research the spatial distribution of potassium monophosphate in drip irrigation the following initial conditions were accepted in this study: soil porosity decreased practically linearly from 0.60 at the surface to 0.49 at the depth of $0.80 \mathrm{~m}$. The specific surface area, vice verse, markedly increased with the deepening from $40 \mathrm{~m}_{2} / \mathrm{g}$ at the soil surface to $46 \mathrm{~m}_{2} / \mathrm{g}$ at $0.80 \mathrm{~m}$ depth. The calculating was done basing on the conditions, 801 of water were being continuously supplied onto the assigned surface point within 20 hours. Previous research on the adequacy of modeling of drip irrigation with pure water on slopes proved that results of modeling correspond well to the experimental data $\mathrm{R}^{2}$ from 0.64 to 0.78 depending on the slope angle [14]. In the present study the processed experimental results contain lower $\mathrm{R}^{2}$ values, namely from 0.56 to 0.68 . It is accounted for by the fact that not water volumes themselves but transferred by them nutrient masses were calculated.

Figures 2 and 3 illustrate significant differences in the final potassium monophosphate distribution in soil according to the results of modeling. Experimental results also confirm that variations take place. The contour shapes affect the root system formation and the nutrients content. After the watering and drying of the soil the nutrients concentrate exactly within the wetting contour boundaries. The figures demonstrate considerable differences of 
contours formed at different initial moisture levels. Since drip irrigation serves to water a number of plants, it is possible to select more presicely the conditions under which the adjusting contours join together. At a lower initial moisture level joining of the contours proceeds slower. That means to achieve the needed joining a larger volume of irrigation water is required.
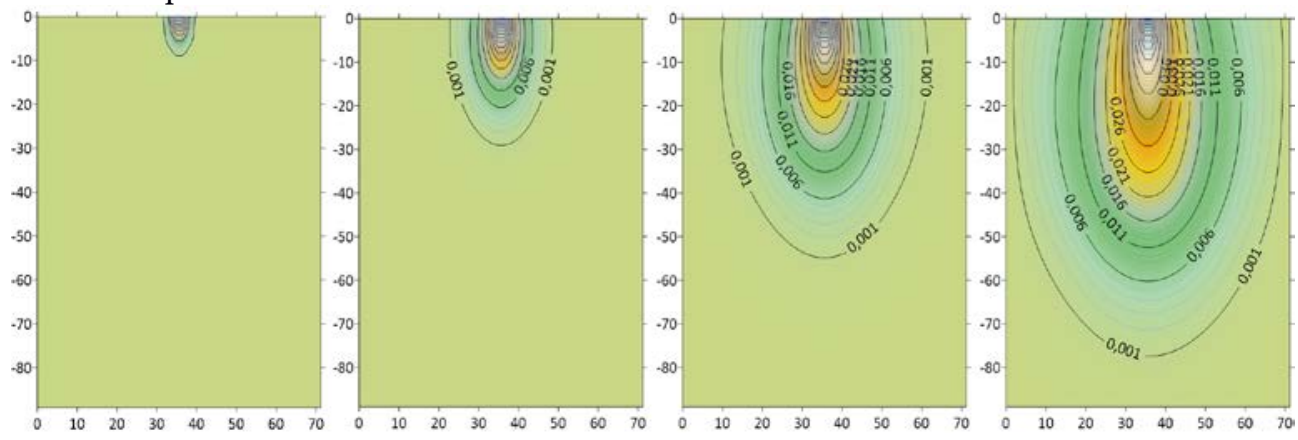

Fig. 2. The dynamics of potassium monophosphate spatial distribution at the initial soil moisture volume 0.4
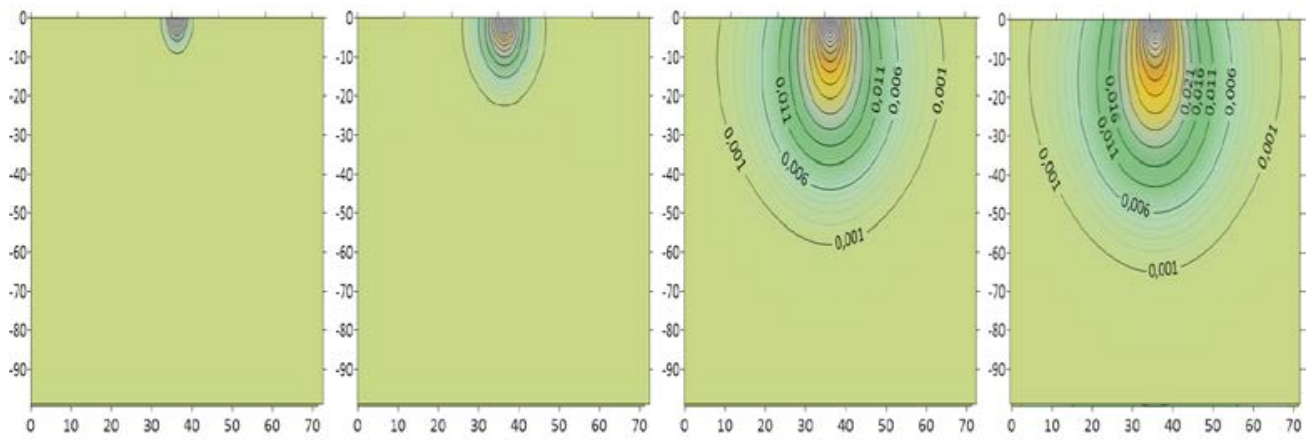

Fig. 3. The dynamics of potassium monophosphate spatial distribution at the initial soil moisture volume 0.2

\section{Conclusion}

Depending on the initial water content in soil the shape and the geometrical size of wetting contours and, consequently, the spatial distribution of potassium monophosphate vary significantly. These variations can be pre-estimated and calculated. Even seemingly minor differences in the initial water content in soil may have a great impact on the final distribution of nutrients in soil which in its turn may influence formation and growth of the plant's root system. The increased nutrients concentration "settling down" as a result of fertigation precisely along the wetting contour boundary determines the root growth direction.

The designed software programme to model nutrients transfer with irrigation water enables the user to set various initial moisture gradients taking into account depth, intervals between drippers, intensity and duration of water supply. The calculations are carried out on the basic hydrophysical soil characteristic and the hydraulic conductivity function. They allow simultaneous following the dynamics of the wetting contours. The software programme is equipped with an interactive graphic interface for primary data processing, soil profile discretization and graphical representation of the results. 


\section{References}

1 A.N. Dmitriev, Resuljtaty pochvenno-meliorativnyh issledovanij pri rekonstruktsii mezhhozyastvennoj orositeljnoj sistemy "Druzhba" Chuvashskoj Respubliki, Melioratsija i vodnoe hozyastvo. № 2. ss. 17-21 (2016)

2 N.M. Abdou, N.N. Dubenok, I.P. Kruzhilin, M.A. Ganiev, K.A. Rodin, Experience drip irrigation rice, Irrigation and Water Management, 3, pp. 14-17 (2014)

3 W.R. Adams, K.T. Zeleke, Diurnal effects on the efficiency of drip irrigation, Irrigation Science, 35(2), pp. 141-157 (2017) https://doi.org/10.1007/s00271-016-0529-1

4 S.K. Biswas, A.R. Akanda, M.S. Rahman, M.A. Hossain, Effect of drip irrigation and mulching on yield, water-use efficiency and economics of tomato, Plant Soil Environ., 61, pp. 97-102 (2015) https://doi.org/10.17221/804/2014-PSE

5 V.V. Borodychev, Optimaljnoe upravlenie polivami na osnove sovremennyh vychisliteljnyh algoritmov, Izvestiya Nizhnevolzhskogo agrouniversitetskogo kompleksa: nauka i vysshee professionaljnoe obrazovanie, №4(40), ss. 21-28 (2015)

6 E.V. Melikhova, E.V. Melikhova, A.F. Rogachev, Computer Simulation and Optimization of Parameters of Configuration of the Contour of Moistening Under Drip Irrigation of Agricultures, Studies in Computational Intelligence, №826, pp. 1193-1201 (2019) DOI: 10.1007/978-3-030-13397-9_122.

7 T. Varga, G.W. Feyereisen, M.P. Russelle, S. Ao, J.A. Coulter, Versatile, precise drip irrigation system for agronomic small-plot research, Paper presented at ASABE 2018 Annual International Meeting, Detroit, United States (2018) https://doi.org/10.13031/aim.201801700

8 A.S. Falkovich, Funktsii vlagoprovodnosti treschinovatyh tenmno-kashtanovyh pochv Zavolzhjya, Agrarnyj nauchnyj zhurnal, № 7, ss. 66-68 (2011)

9 V.N. Shkura, Ob uchete pochvennyh vodno-fizicheskih harakteristik pri opredelenii parametrov konturov kapeljnogo uvlazhneniya pochvy, Nauchnyj zhurnal Rossijskogo NII problem melioratsii, №4(28), ss. 137-153 (2017) https://elibrary.ru/item.asp?id=30519557

10 V.V. Alekseev, Automation of determining the contact angle of washing liquids wetting, J. Phys.: Conf. Ser. 1333042001 (2019)

11 N.V. Byshov, Changing the Contact Wetting Angles when Adding Surface-Active Substances to Washing Solutions, Engineering Technologies and Systems, 29(2), pp. 295-305 (2019) DOI: https://doi.org/10.15507/2658-4123.029.201902.295-305

12 V.A. Sysuev, Poluchenie osnovnoj gidrofizicheskoj harakteristiki pochv na osnove idealizirovannyh modelej, Doklady Rossijskoj akademii seljskohozyajstvennyh nauk, № 5, ss. 63-66 (2013)

13 V.V. Alekseev, Hydrophysical aspects of soil assessment in melioration, IOP Conference Series: Earth and Environmental Science, Vol. 341, 012106, 6 p. (2019) DOI:10.1088/1755-1315/341/1/012106

14 V.V. Alekseev, Simulation of drip irrigation on slope lands, BIO Web of Conferences (FIES 2019), Vol. 17, 00218, 5 p (2020) https://doi.org/10.1051/bioconf/20201700218 